\title{
Transparent Photocatalytic Thin Films on Flexible Polymer Substrates
}

\author{
Nives Vodišek ${ }^{1}$, Andraž Šuligoj ${ }^{2,3}$, Dorota Korte ${ }^{1}$ and Urška Lavrenčič Štangar ${ }^{1,2, *(1)}$ \\ 1 Laboratory for Environmental and Life Sciences, University of Nova Gorica, SI-5001 Nova Gorica, Slovenia; \\ nives.vodisek@gmail.com (N.V.); dorota.korte@ung.si (D.K.) \\ 2 Faculty of Chemistry and Chemical Technology, University of Ljubljana, SI-1000 Ljubljana, Slovenia; \\ andraz.suligoj@fkkt.uni-lj.si \\ 3 National Institute of Chemistry, SI-1000 Ljubljana, Slovenia \\ * Correspondence: urska.lavrencic.stangar@fkkt.uni-lj.si; Tel.: +386-1-479-8528
}

Received: 3 August 2018; Accepted: 6 October 2018; Published: 11 October 2018

check for updates

\begin{abstract}
Self-cleaning and/or photocatalytic films on polymer substrates have found numerous applications during the past decades. However, the common demand for high-temperature post synthesis treatment limits the application to temperature resistant substrates only. Herein, we prepared self-cleaning photocatalytic films on four thermosensitive polymeric substrates: polyvinyl chloride (PVC), polymethyl methacrylate (PMMA), and acryl coated polyester (PES) fabric (D2) with poly(vinylidene fluoride) (PVDF) containing lacquer (D1). $\mathrm{TiO}_{2}$ was prepared via a low-temperature sol-gel process using titanium(IV) isopropoxide and zirconium(IV) butoxide as precursors with various loading levels of $\mathrm{Zr} ; 0,5,10$, and $20 \mathrm{~mol} \%$, and deposited on the substrates by using a $\mathrm{SiO}_{2}$ binder in form of thin films (ca. $200 \mathrm{~nm}$ thick) via dip-coating. The films were characterized by SEM, hardness test, UV-Vis, photothermal beam deflection spectroscopy, and IR spectroscopy, while photocatalytic activity was measured by the fluorescence-based method of the terephthalic acid probe and wetting by contact angle measurements. Films containing $10 \mathrm{~mol} . \%$ of $\mathrm{Zr}$ showed the best compromise regarding photocatalytic activity and mechanical stability while from substrates point of view PVC performed the best, followed by PMMA, D1, and D2. The beneficial role of $\mathrm{SiO}_{2}$ binder was not only guaranteeing excellent mechanical stability, but also to prevent the D1 polymer from deterioration; the latter was found to be labile to long-term solar-light exposure due to degradation of the top PVDF layer.
\end{abstract}

Keywords: photocatalysis; self-cleaning surface; $\mathrm{TiO}_{2} ; \mathrm{ZrO}_{2} ; \mathrm{SiO}_{2}$; transparent films; thermosensitive substrates; PMMA; PVC; PES; PVDF

\section{Introduction}

Nature-inspired self-cleaning surfaces that are usually either superhydrophobic or superhydrophilic have been getting more and more attention over the years [1,2]. The superhydrophilic effect can be achieved by changing the (nano)structure or chemistry of the surface and can be accomplished via "bottom-up" or "top-down" methods [1]. In the former approach, an active agent is synthesised, which often comprises of nanoparticles, thus functioning not only as a catalyst for cleaning purposes, but also as a component directing the final nanostructure of the material surface. As such, titanium dioxide $\left(\mathrm{TiO}_{2}\right)$ has been reported numerous times as the active component of the self-cleaning films [3,4]. However, $\mathrm{TiO}_{2}$ has some limitations since it reduces the total transmittance of the films and the non-hydrophilic water contact angle in the dark is usually quickly re-established. Also, it has a relatively high band gap ( $3.2 \mathrm{eV}$ for anatase), hence being limited to UV-illumination only. In order to circumvent these limitations, composites with other oxides have been proposed. 
$\mathrm{ZrO}_{2}$ is known for its high permittivity, semiconducting behaviour, and thermal stability; it can thus be used with titania in photocatalytic applications. Moreover, it has a high coefficient of expansion and thus results in a reduced formation of cracks during annealing. It was reported that coupling those two semiconductors can prevent anatase to rutile phase transformation of $\mathrm{TiO}_{2}$ while calcination [5-7] and by increasing the surface area and forming new surface sites, it can additionally improve photocatalytic activity. Also, the incorporation of $\mathrm{ZrO}_{2}$ in $\mathrm{TiO}_{2}$ improves mechanical stability and decreased the ageing effect of $\mathrm{TiO}_{2}$ [8].

On the other hand, $\mathrm{SiO}_{2}$ can be applied as a protective layer for a soda-lime glass to prevent harmful migration of $\mathrm{Na}^{+}$from the substrate into the $\mathrm{TiO}_{2}$ layer during the high-temperature heat treatment [9]. $\mathrm{SiO}_{2}$ has also been reported to pronounce the hydrophilicity of films, which can be maintained even in the dark $[4,10,11]$. Last but not least, $\mathrm{SiO}_{2}$ acts as a binding component, improving adherence to the substrate, mainly glass [8], and also acts as a dispersing agent for $\mathrm{TiO}_{2}$ nanoparticles [12].

Photocatalytic thin films have found applications on various surfaces, for example, glass, plastics [13-15], textiles [16-25], concrete [26-28], tiles [29,30], facade [28,31,32], mirrors [26,33,34], polymer membranes $[35,36]$, etc. Polymeric substrates are challenging for various reasons: (i) they are commonly thermosensitive; (ii) proper adhesion of the films and their long-term stability are hard to achieve; (iii) homogeneity, transparency, and unchanged optical properties of substrates is also difficult to achieve; and very importantly, (iv) photo-yellowing and photodegradation of organic substrate is commonly observed in such systems. We chose the dip-coating procedure for thin films deposition, which demands a preparation of proper solution with suitable rheological properties. In the literature, we came across different approaches to prepare polymeric substrates, use of various surface pre-treatment method [37,38], or use of special deposition technique [39-42]; in other cases, various additives were used and binders to provide a better adhesion of the film [43,44]. $\mathrm{SiO}_{2}$ is often chosen as a protective layer in such substrates $[24,45,46]$ for means of preventing the photodegradation of the substrate.

Herein, zirconia and silica were incorporated into the titania film structure to study their multifaceted influence, following the successful application of such a sol system on glass substrates previously reported [8]. The films were prepared via low-temperature procedure and it can be applied to many substrates because such films do not demand high-temperature post-treatment. The substrates of choice were polyvinyl chloride (PVC), polymethyl methacrylate (PMMA), and highly studied poly(vinylidene fluoride) (PVDF) coating. The photocatalytic activities were thoroughly investigated by contact angle measurements and by following the oxidation of terephthalic acid; additionally, the long-term stability of the films and a prevention strategy against photo-yellowing of the polymers, which involves the incorporation of $\mathrm{SiO}_{2}$ is finally discussed.

\section{Materials and Methods}

\subsection{Materials}

Chemicals that we used in this study are: tetraethyl orthosilicate (TEOS, 98\%) from Acros Organics (Geel, Belgium); titanium(IV) isopropoxide (TTIP, 98\%), zirconium(IV) butoxide (ZTB, $80 \mathrm{wt} \%$ ) from Aldrich (Steinheim, Germany); terephthalic acid (TPA) from Alfa Aesar (Karlsruhe, Germany), absolute ethanol, hydrochloric acid (37\%), 2-propanol from Carlo Erba (Val de Reuil, France); hydroxyethyl-cellulose (HEC $2 \mathrm{wt} \%$ ) from Fluka; ethanol (96\%) from Itrij (Radovljica, Slovenia); Levasil 200/30\% from Obermeier (Bad-Berleburg, Germany); perchloric acid (70\%), 2-propoxyethanol, 1-propanol, and Resazurin and Glycerol (99.5\%) from Sigma-Aldrich (Steinheim, Germany), and $\mathrm{NaOH}$ from VWR (Wien, Austria). 


\subsection{Preparation of the Materials}

The $\mathrm{TiO}_{2}$ sol was prepared through sol-gel reflux processing, as previously described [8] by dissolving TTIP, absolute ethanol, and ZTB; as a peptizing agent, an aqueous solution of $\mathrm{HClO}_{4}$ was used. Molar percentage ratio of $\mathrm{Zr} / \mathrm{Ti}$ was varied by varying the amount of zirconium(IV) butoxide at fixed TTIP. As a result, a series of samples were prepared with $\mathrm{Zr} / \mathrm{Ti}$ molar ratio of $5 \%, 10 \%$, and $20 \%$. The obtained samples were designated as Ti5Zr, Ti10Zr, and Ti20Zr, respectively. $\mathrm{Pure}^{\mathrm{TiO}} 2$ was also synthesized by the same procedure, without adding the ZTB and it was designated as Ti0Zr. $\mathrm{SiO}_{2}$ binder solution was prepared from TEOS, colloidal $\mathrm{SiO}_{2}$ (Levasil 200/30\%), $\mathrm{HCl}$, and 2-propanol. 1-propanol and 2-propoxyethanol were finally added to produce a solution with suitable rheological properties [8]. $\mathrm{TiO}_{2}$ and $\mathrm{SiO}_{2}$ sols were combined and mixed thoroughly overnight. This sol was then deposited by the dip-coating technique with immersion and withdrawal speed of $100 \mathrm{~mm} / \mathrm{min}$ on four different polymer substrates: PVC foil, PMMA, D1, and D2. Composition and thermal stability of the substrates are given in Table 1. After dip-coating, the samples were dried first with a blow-dryer and then with heat-gun (Black\&Decker) for $30 \mathrm{~s}$ on each side from ca. $30 \mathrm{~cm}$ distance. On every substrate, the coating-heating cycle was repeated to obtain three layers of each sample.

Table 1. Main characteristics of substrates.

\begin{tabular}{|c|c|}
\hline Substrate Label & Description \\
\hline D1 & $\begin{array}{l}\text { Acryl coated } 100 \% \text { PES fabric ( } 1100 \mathrm{dtex}) \text { with PVDF containing lacquer, white, } 1 \mathrm{~mm} \\
\text { thickness. Temperature resistance between }-30 \text { and }+70^{\circ} \mathrm{C} \text {. UVA /B stable. Sioen, Belgium. }\end{array}$ \\
\hline D2 & $\begin{array}{l}\text { Acryl coated } 100 \% \text { PES fabric (1100 dtex), white, } 1 \mathrm{~mm} \text { thickness. Temperature resistance } \\
\text { between }-30 \text { and }+70^{\circ} \mathrm{C} \text {. UVA/B stable. Sioen, Belgium. }\end{array}$ \\
\hline PVC_s & $\begin{array}{l}\text { PVC foil. Transparent, } 0.1 \mathrm{~mm} \text { thickness, the temperature of glass transition around } 80^{\circ} \mathrm{C} \text {, } \\
\text { melting temperature of } 100^{\circ} \mathrm{C} .\end{array}$ \\
\hline PMMA & $\begin{array}{c}\text { Polymethyl methacrylate sheet. Transparent, } 3 \mathrm{~mm} \text { thickness, temperature of glass transition } \\
\text { around } 85^{\circ} \mathrm{C} \text {, melting temperature around } 130^{\circ} \mathrm{C} .\end{array}$ \\
\hline
\end{tabular}

\subsection{Characterization}

Specific surface area was determined according to multi-point Brunauer-Emmett-Teller theory (BET) and thermal analyses were conducted on thermogravimeter and differential scanning calorimeter (TGA-DSC) on analogous powder samples. These results are presented in our previous research paper [8]. Fourier-transform infrared (FTIR) spectra from 4000 to $400 \mathrm{~cm}^{-1}$ were obtained by Perkin Elmer 100 with GladiATR ${ }^{\text {TM }}$ Single Reflection ATR Accessory (PIKE Technologies, Madison, WI, USA), X-ray powder diffraction (XRD) patterns were obtained with RIGAKU MiniFlex 600 (Rigaku, Tokyo, Japan) with the copper source, providing X-rays of the wavelength of $1.54 \AA$. The diffraction data were collected in the $2 \Theta$ range of $20-80^{\circ}$. From XRD data, size of nanocrystalline anatase particles was calculated by the Scherrer equation. UV-Vis transmittance of the thin films and diffuse reflectance spectroscopy (DRS) measurements of the powder analogues were performed on Lambda 650 Perkin Elmer (PerkinElmer, Waltham, MA, USA) in the range of 200 to $800 \mathrm{~nm}$. The powder samples for $\mathrm{XRD}$ and UV-Vis DRS measurements were derived from the corresponding deposits of the solutions after heat treatment at $150{ }^{\circ} \mathrm{C}$. Additionally, band gap values of the semiconducting thin films were determined by the photothermal technique [39,40] that is Beam Deflection Spectroscopy (BDS) [47].

The BDS technique was performed using the lab-built experimental setup that is presented in Figure 1. The sample is illuminated by an intensity modulated light beam (pump beam) [47] from a solid state laser (Coherent, OBIS 455) with $450 \mathrm{~nm}$ and $50 \mathrm{~mW}$ of output wavelength and power, respectively. It is modulated by mechanical chopper (SCITEC INSTRUMENTS, Control unit model $300 \mathrm{C}$, chopping head model $300 \mathrm{CD}$, chopping disks model 300H, Scitec Instruments Ltd, Wiltshire, $\mathrm{UK})$, and heats the sample perpendicularly to its surface. The sample is placed on a three-dimensional (3D) translation stage (CVI, Model $2480 \mathrm{M} / 2488$ ) to vary its position in $x, y$ and $z$-direction and to optimize the experimental configuration. The absorbed energy induces temperature oscillations 
(TOs) not only in the sample but also in its surroundings. The TOs are probed by He-Ne laser beam (probe beam) of $632.8 \mathrm{~nm}$ output wavelength and $2 \mathrm{~mW}$ output power (Model 25-LGR-393-230, CVI MELLES GRIOT, Pittsfield, MA, USA). The interaction of probe beam (PB) with TOs results in PB intensity change that is detected by a quadrant photodiode (Model C30846E, RBM-R. Braumann $\mathrm{GmbH}$, Langenbach, Germany) equipped with an interference filter (Edmund Optics) and connected to the lock-in amplifier (Stanford research instruments, Model SR830 DSP).

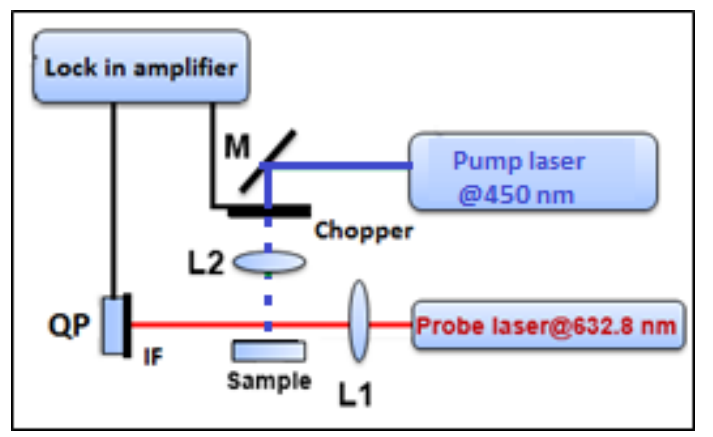

Figure 1. Schematic of the beam deflection spectroscopy (BDS) experimental setup. L1, L2: lenses, M: reflecting mirrors, IF: interference filter, QP: quadrant photodiode.

Scanning electron microscopy (SEM,) images were obtained on a Zeiss Supra 35 VP microscope (Carl Zeiss NTS GmbH, Oberkochen, Germany) operating at $1 \mathrm{kV}$. The samples were pre-coated with carbon (ca. $8 \mathrm{~nm}$ ).

The mechanical scratch resistance of the films was determined by a pencil hardness test (ISO15184:1998) using Elcometer 501 (Elcometer Instruments, Manchester, United Kingdom). ATR FTIR spectra from 4000 to $400 \mathrm{~cm}^{-1}$ with the resolution of $4 \mathrm{~cm}^{-1}$ were obtained by Perkin Elmer 100 with GladiATR ${ }^{\mathrm{TM}}$ Single Reflection ATR Accessory. Samples during contact angle measurements and resazurin test were irradiated in a UV chamber set at $\lambda_{\max }=365 \mathrm{~nm}$ and $2.3 \mathrm{~mW} / \mathrm{cm}^{2}$ of power. Suntest XLS+ from Atlas, USA, was used for the prolonged irradiation of D1 sample (Xenon light, daylight filter, irradiation intensity $750 \mathrm{~W} / \mathrm{m}^{2}(300-800 \mathrm{~nm})$, with UVA fraction of $\left.0.62 \mathrm{~W} / \mathrm{m}^{2}(300-400 \mathrm{~nm})\right)$ to determine the possible damage upon ageing. Contact angle measurements were carried out on goniometer CAM 100 from KSV instruments (KSV Instruments, Finland).

\subsection{Photocatalytic Activity}

Photocatalytic activity was determined by the fluorescence-based method with terephthalic acid $[8,48]$. A mixture containing terephthalic acid, an aqueous solution of $\mathrm{NaOH}$ and ethanol-based HEC solution was deposited on the catalyst surface with the dip-coating technique (withdrawal speed $10 \mathrm{~cm} / \mathrm{min})$. Before the deposition, samples were irradiated for one hour $\left(\lambda_{\max }=365 \mathrm{~nm}\right.$, $2.3 \mathrm{~mW} / \mathrm{cm}^{2}$ ). After coating with TPA, they were placed back in the UVA chamber. During illumination, samples for analyses were obtained by periodically washing off the TPA layer with a mixture of ethanol/water solution $\left(0.25 \mathrm{~mL} / \mathrm{cm}^{2}\right)$. Fluorescence in the collected samples-due to the formation of hydroxyterephthalic acid (HTPA), a hydroxyl radical product of TPA—was analyzed by using microtiter plate reader spectrofluorometer (Infinite F200 Microplate Reader, Tecan, Männedorf, Switzerland), with an excitation wavelength $320 \mathrm{~nm}$ and emission wavelength $430 \mathrm{~nm}$.

The activity of thin films was also visually tested with resazurin (Rz) dye test. The Rz solution was prepared by dissolving $\mathrm{Rz}$ dye $(250 \mathrm{mg})$ in deionized water $(50 \mathrm{~mL})$ and mixed overnight to completely dissolve the dye. A sacrificial agent (e.g., glycerol) for the photogenerated holes was not used, as we wanted to test the wetting of the surface also. Hence, generated holes react with water (or surface $-\mathrm{OH})$ and prevent electron-hole recombination. A drop $(0.5 \mathrm{~mL})$ of such prepared Rz ink was put on the surfaces. Samples were then put in the UVA chamber and irradiated by UV light; photos were taken in $15 \mathrm{~min}$ intervals for $2 \mathrm{~h}$ to observe the kinetics. 


\section{Results and Discussion}

\subsection{Materials Characterization}

X-ray powder diffraction (XRD) patterns of the samples with various Zr content are presented in Figure 2. In all samples diffraction peaks at $25^{\circ}, 38^{\circ}, 48^{\circ}, 54^{\circ}$, and $63^{\circ}$ are observed despite low-temperature preparation route and are assigned to anatase reflection planes (101), (004), (200), (105), and (204), respectively [49,50]. Less intense diffraction peak at around $30^{\circ}$ is ascribed to brookite $\mathrm{TiO}_{2}$ phase reflection plane (121) [51], which is present as a minor crystalline phase. As expected, the presence of zirconia and silica is not reflected in the diffraction patterns due to the amorphous character of these phases. XRD patterns showed that with higher loading of Zr, diffractions are sharper, which also indicates the increase of the anatase crystallite size. Particle sizes from XRD patterns were calculated by using the Scherrer equation based on the full width at the half maximum (FWHM) of the (101) diffraction peak. Thus calculated sizes are presented in Table 2.

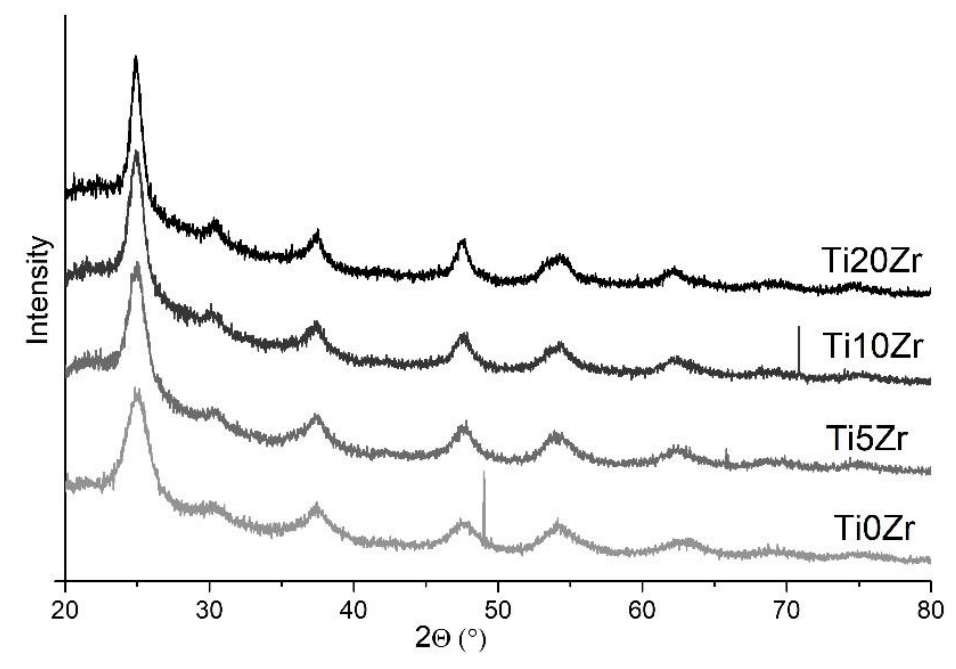

Figure 2. X-ray powder diffraction (XRD) powder patterns.

In Figure 3 UV-Vis transmittance spectra of the films on PVC_s and PMMA are shown, omitting the D1 and D2 substrates since they are not transparent. The coated samples show a higher transmittance than bare substrates in the visible region; the reason being the presence of silica, which has an antireflective property [52-55]. As the PMMA substrate does not transmit the UV light below $360 \mathrm{~nm}$, no major difference among them is observed in the UV region. On the other hand, the PVC_s substrate transmits a significant portion of the UV light, hence differences can be seen. The substrate only starts to strongly absorb at $\lambda<320 \mathrm{~nm}$ but upon deposition of the photocatalyst thin films the transmittance margin of the samples shifts to higher wavelengths i.e., $350 \mathrm{~nm}$ (inset in Figure 3), which is close to the absorption edge of $\mathrm{TiO}_{2}$.

For this reason, we determined the band gap energies of the samples. They were obtained by two different methods, i.e., UV-Vis diffuse reflectance using powders and with laser beam deflection spectroscopy (BDS) using thin films [47]. Regarding the former method, one can determine the indirect band gap (Kubelka-Munk model) from the plot $\left(F(R)^{*} h v\right)^{1 / 2}$ vs. $h v$, where $F(R)=\left(1-R_{\infty}\right)^{2} / 2 R_{\infty}[56]$. Values of the band gap are decreasing with the increased size of the crystallites (Table 2).

As regarding the BDS band gap measurements, the amplitude and phase of the signal are collected as a function of the modulation frequency of the pump beam for the unmodified and TiXZr composite samples (Figure 4). 

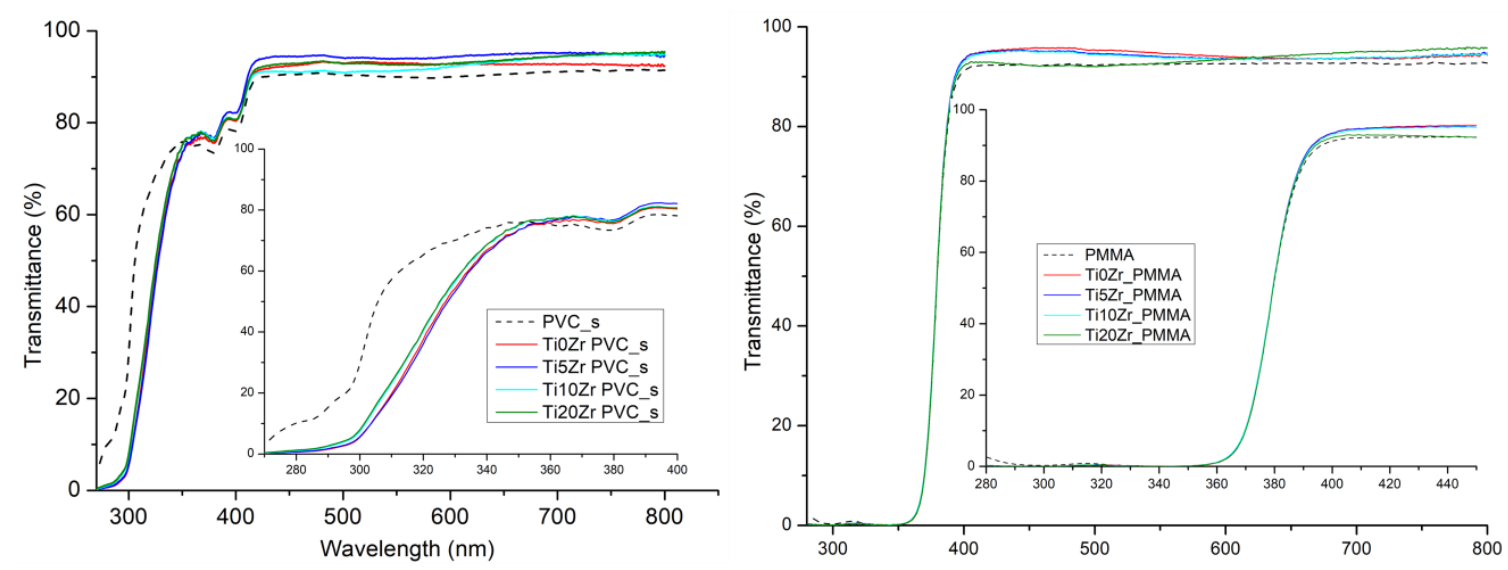

Figure 3. UV-Vis transmittance spectra for polyvinyl chloride (PVC_s) (left) and polymethyl methacrylate (PMMA) (right) samples.
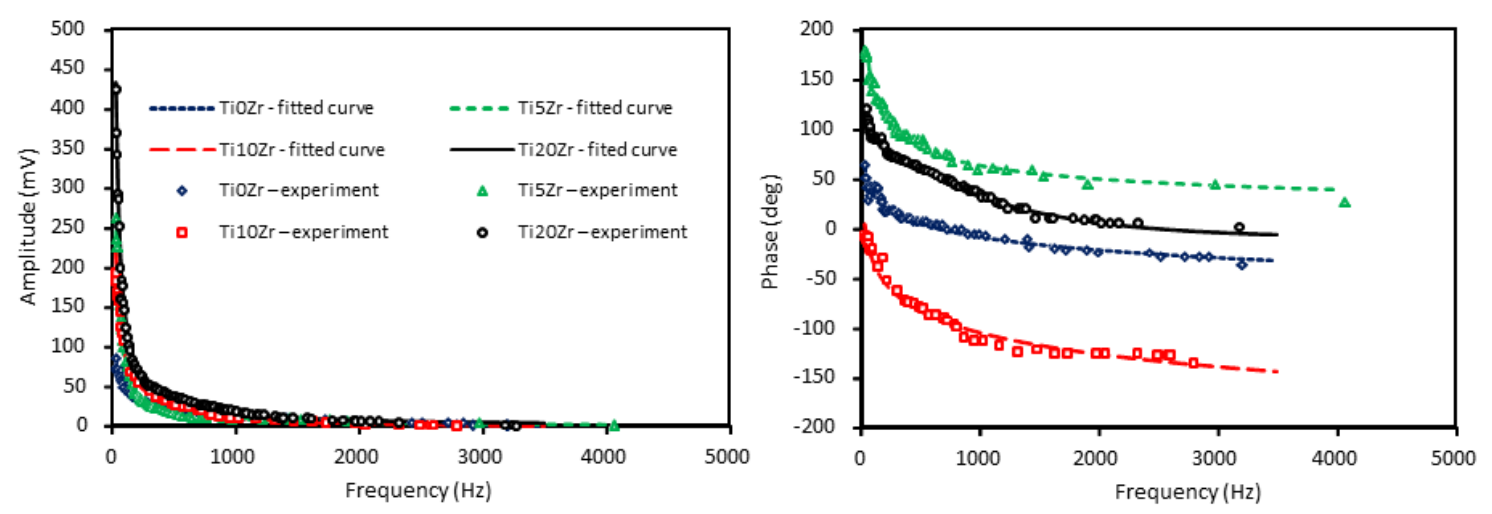

Figure 4. The amplitude (left) and phase of BDS signal (right) for unmodified and Zr-modified composite samples. Points represent the experimental data whereas continuous lines the best fitting using model presented in [47].

It is seen that the signal falls off exponentially with the increase in the modulation frequency of the TOs. Thus, to optimize the experimental conditions the probe beam is tightly focused and carefully aligned close to the sample surface, just to skim it. For that reason, the measurement is performed on flat samples with small lateral dimensions. Furthermore, both the amplitude and phase of the BDS signal are sensitive to optical properties (energy band gap) of the examined samples, what allows for determining its value on the basis of the least-squares method of fitting the theoretical curve to the experimental data [47]. The best theoretical fitting to the experimental data is obtained for the band gap values presented in Table 2. The variation in the value of the energy band gap that was caused by the introduction of $\mathrm{ZrO}_{2}$ into the $\mathrm{TiO}_{2}$ material is rather low (approximately $5 \%$ ) and it can be attributed to the effective value of the whole composite and its changes in composition.

Comparing the two methods, the values match very well and the trend is the same while using both methods. With higher loadings of $\mathrm{Zr}$, the band gap energy is decreasing, which is inversely correlating with the anatase particle size (Table 2); Ti0Zr has the smallest and Ti20Zr the biggest particles. Moreover, it is also well agreed with the data reported elsewhere [57] and it can be described by the quantum size effect. 
Table 2. Band gap and grain size values.

\begin{tabular}{cccc}
\hline Sample & Band Gap-Film $^{\mathbf{a}}$ & Band Gap-Powder $^{\mathbf{b}}$ & Anatase Crystallite Size (101) $^{\mathbf{c}}$ \\
\hline Ti0Zr & $3.30 \mathrm{eV}$ & $3.23 \mathrm{eV}$ & $4.2 \mathrm{~nm}$ \\
Ti5Zr & $3.20 \mathrm{eV}$ & $3.16 \mathrm{eV}$ & $5.0 \mathrm{~nm}$ \\
Ti10Zr & $3.15 \mathrm{eV}$ & $3.11 \mathrm{eV}$ & $5.8 \mathrm{~nm}$ \\
T20Zr & $3.05 \mathrm{eV}$ & $3.09 \mathrm{eV}$ & $7.7 \mathrm{~nm}$ \\
\hline
\end{tabular}

${ }^{\mathrm{a}}$ Determined by BDS; ${ }^{\mathrm{b}}$ Determined by DRS UV-Vis; ${ }^{\mathrm{c}}$ Calculated with the Scherrer equation from XRD data based on the FWHM of the (101) diffraction peak.

In Figure 5 typical SEM images of the Ti0Zr and Ti10Zr thin films on PVC_s, D1, D2, and PMMA substrates are presented. The growth of the particles size and a trend towards better-resolved shapes can be seen in the 0 to $10 \% \mathrm{Zr}$ sample series. Also, the structure of the films is clearly rougher upon $\mathrm{Zr}$ introduction, which is in agreement with our previous publication with such films deposited on glass substrates [8].
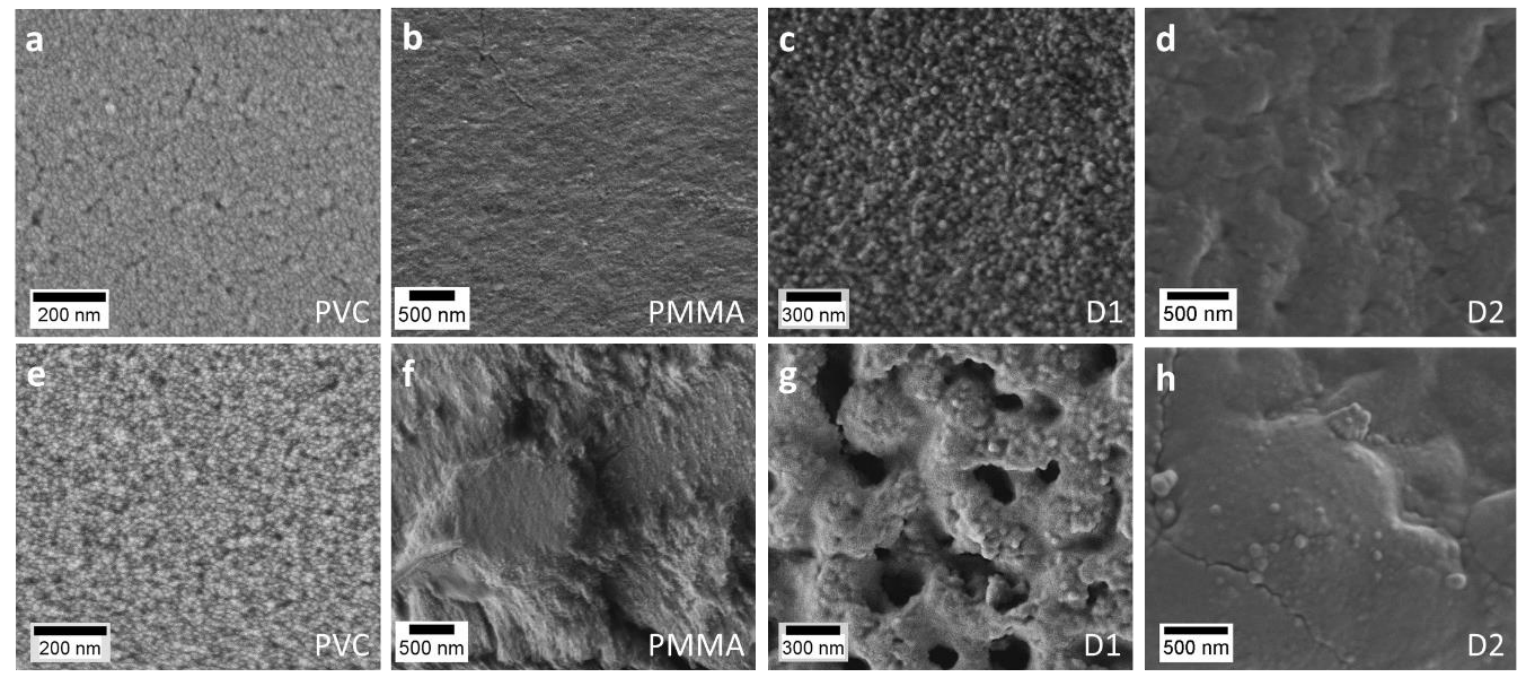

Figure 5. Typical scanning electron microscopy (SEM) images of Ti0Zr film (a-d) and Ti10Zr film $(\mathbf{e}-\mathbf{h})$ on four different substrates: PVC_s (a,e), PMMA (b,f), D1 (c, g), and D2 (d,h).

Mechanical stability tests were not possible to be conducted on substrates D1 and D2, because of the too rough texture of these substrates (PES fabric inside). Mechanical stability of PVC_s and PMMA specimen (Figure 6) show that the highest stability was obtained on the sample with the highest $\mathrm{Zr}$ content on both substrates, while sample without $\mathrm{Zr}$ was the least mechanically stable. Interestingly, although the trend of higher scratch resistance with higher $\mathrm{Zr}$ concentrations is present in both substrates, lower $\mathrm{Zr}$ loadings ( 0 and 5\%) performed better on PVC_s substrate, while 10\% loading shows higher stability with PMMA substrate relative to PVC_s. We also performed a scratch test on one-year-old PVC_s films stored in the dark (Figure 6). The Ti20Zr retained the stability, but the other three films lost their mechanical stability for one or two pencil hardness, which is in agreement with the measurements on glass substrates [8].

Surface properties were evaluated by measuring water contact angles (WCA) and they are shown in Figure 7. The WCAs of bare substrates were approximately $85^{\circ}$ except for PMMA $\left(65^{\circ}\right)$ and D1 $\left(95^{\circ}\right)$; the high WCA of the latter is the consequence of the presence of fluorine in the PVDF top layer, which is not present in the D2 neat substrate. The WCAs of all bare substrates do not show significant change after $3 \mathrm{~h}$ of UV irradiation. On the other hand, coating the surfaces with $\mathrm{TiO}_{2}$ films showed much lower initial WCAs in PVC_s $\left(15-25^{\circ}\right)$ and PMMA $\left(15-20^{\circ}\right)$ substrates; it did not, however, affect the D1 and D2 initial WCAs-they remained relatively high, i.e., $70^{\circ}$ and $80^{\circ}$ for D2 and D1 substrate, respectively. Upon irradiation, the WCAs decreased in PVC_s and PMMA substrates, although no clear correlation 
can be deduced regarding the concentration of $\mathrm{Zr}$ in the $\mathrm{TiO}_{2}$ film. Interestingly, the WCAs of films on D1 and D2 substrates actually increased upon irradiation, although mostly not in a statistically significant manner. From these observations, we can conclude that the films are highly active on PVC_s and PMMA substrates but not on acryl coated PES substrates. However, hydrophilicity might not be the most important measure related to the photocatalytic activity for surfaces [58] due to their high dependence on surface charge and roughness, i.e., D1 and D2 exhibited millimetre-sized textural features, hence the determination of WCAs was difficult and varied greatly due to such surface effects.

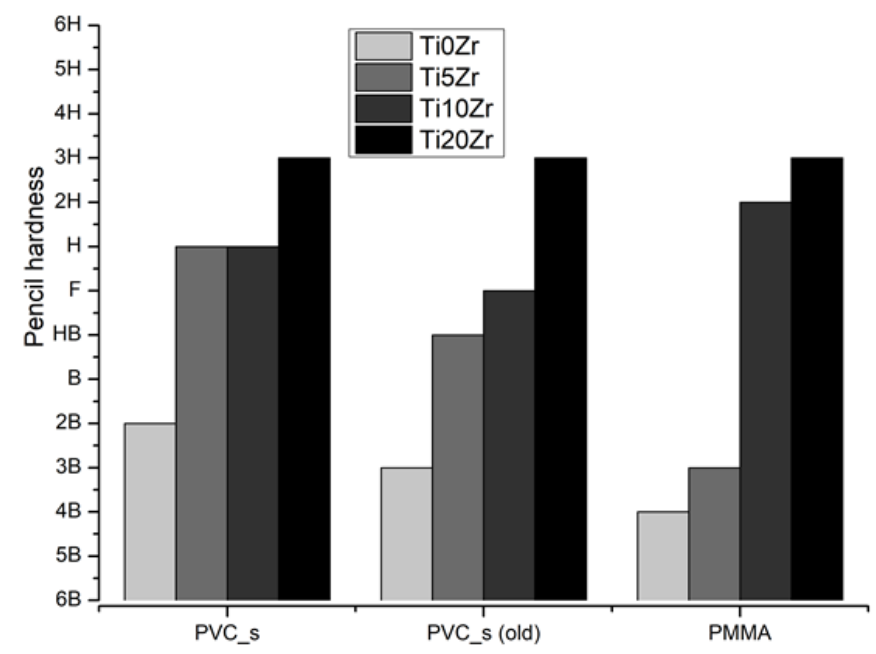

Figure 6. Mechanical stability measured by hardness pencil test.
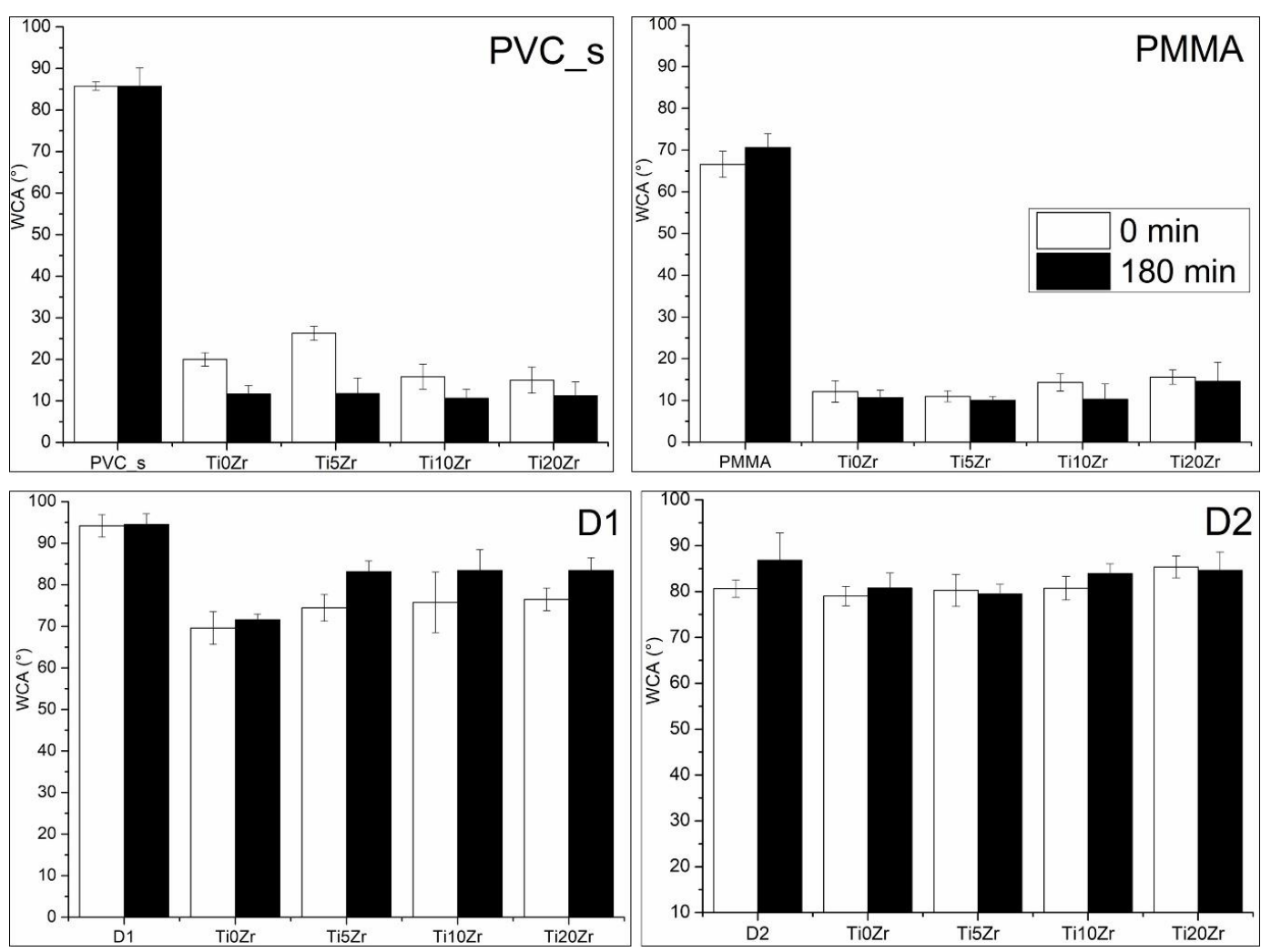

Figure 7. Water contact angle values for films with various $\mathrm{Zr}$ concentration deposited on different substrates, as marked by their first columns. Error bars represent standard error of the mean $(\mathrm{N}=5)$. 


\subsection{Photocatalytic Activities}

To determine photocatalytic activities, we conducted measurements of the HTPA formation rate on films (Figure 8). Generally, the addition of zirconium decreased the photoactivity of the films, regardless of the substrate used. This is in accordance with our previous study on glass substrates [8] and the reason for such a trend can be attributed to larger crystal size and consequently lower surface area, together with an increasing portion of inactive zirconia phase. Interestingly, the lowering of the activity with $20 \% \mathrm{Zr}$ addition is similar in all of the substrates used ( $70 \%$ decrease), except for D2 substrate where activity was lowered for only $44 \%$ (not statistically significant). However, this sample also showed the lowest activity in general. The reasons for this are still unclear.

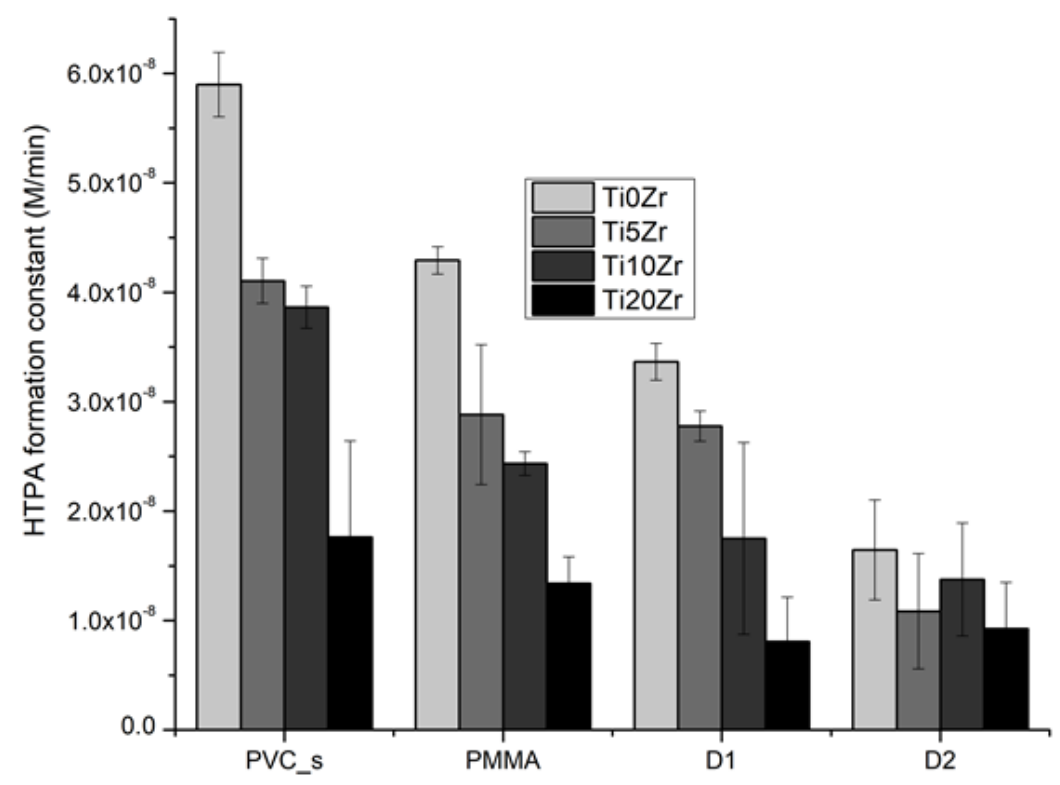

Figure 8. Photocatalytic activities determined by the formation constant of hydroxyterephthalic acid. Error bars represent standard error of the mean $(\mathrm{N}=3$; three different spots on the sample, as suggested in ref. [48]).

The third and more visible-oriented photocatalytic test was the reduction of resazurin dye on the surface of the materials (Figure 9). Clearly, the neat substrates showed no discolouration of the dye, even though the irradiation source was UV-light. The wetting of the surface with increasing irradiation times was observable in substrates PVC_s and PMMA, while in D1 and D2 substrates, this effect was not seen, thus confirming their less hydrophilic nature when compared to PMMA and PVC_s. Among the latter two, PMMA is showing faster wetting of the surface with the resazurin, which is in accordance with the WCAs of these substrates, i.e., PMMA showed more hydrophilic nature. Regarding the reduction of resazurin, only PVC_s and PMMA substrates showed a remarkable reduction of resazurin to resorufin (pink) and even further to dihydroresorufin (colorless), as shown in the Figure 9. PMMA, however, showed slightly higher discolouration at final irradiation times (Figure S1). Generally, a higher percentage of Zr produced smaller discolouration in PVC_s and PMMA substrates, while D1 and D2 samples were less active, and such a trend was not observed. D2 substrate showed a measurable blue colour change, while this was not the case in the D1 substrate. We can conclude that the $\mathrm{TiO}_{2} / \mathrm{SiO}_{2}$ films on PMMA and PVC_s substrates were more successful in photocatalytic degradation; they were more active in TPA oxidation and resazurin reduction as compared to the D1 and D2 substrates. 

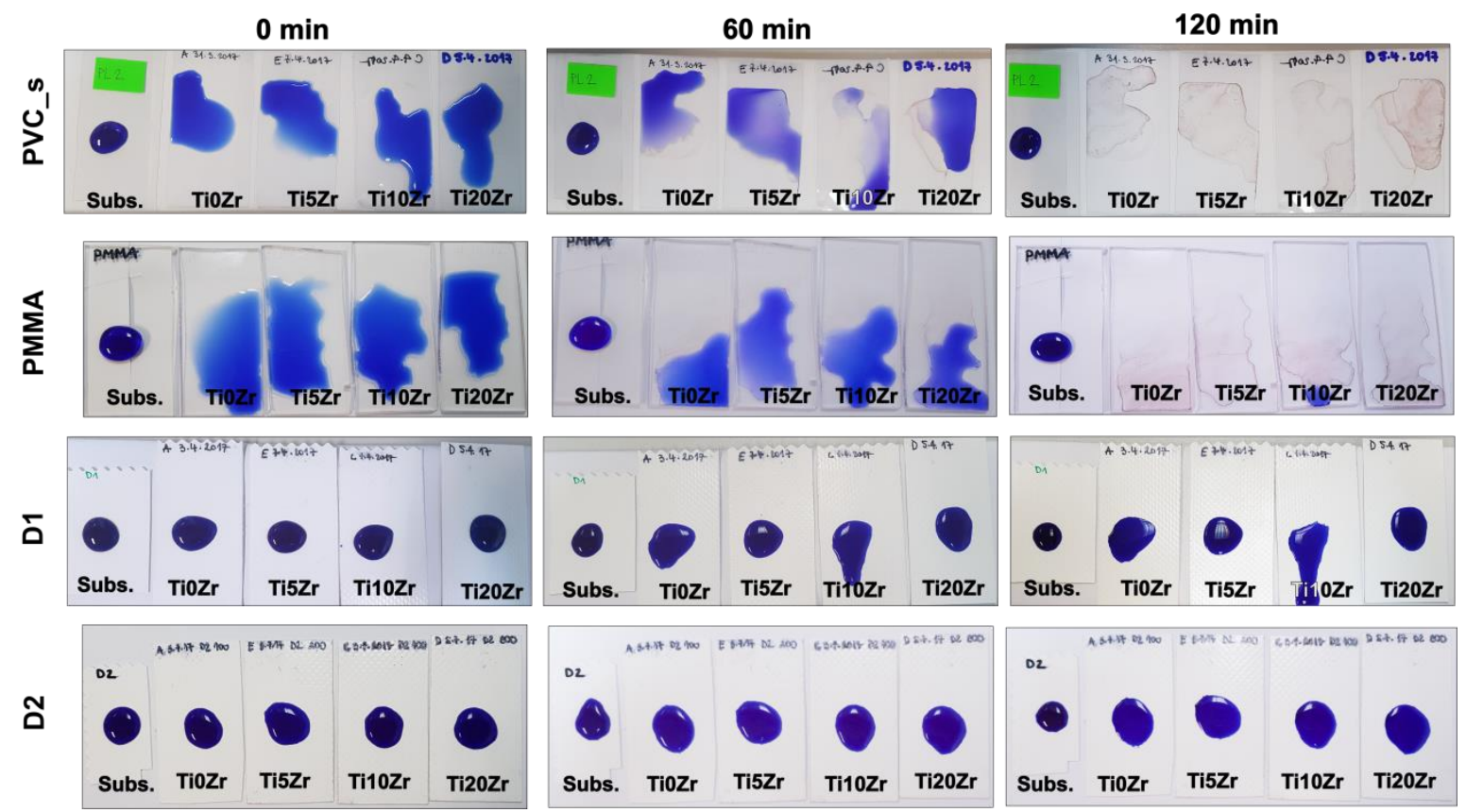

Figure 9. Degradation of the resazurin dye under UV light for substrates PVC (a), PMMA (b), D1 (c), and D2 (d).

\subsection{Photostabilities of the Materials}

The instability of acrylic coatings in the presence of $\mathrm{TiO}_{2}$ and UV-irradiation has been described in the literature [59]. The resistance of PVDF membranes has also been investigated, especially for application in electronic devices [60]. A degradation of the chosen polymeric substrates could be expected due to the formation of the highly reactive radicals or $\mathrm{h}^{+}$themselves by the photocatalyst layer, as confirmed by the HTPA test.

Hence, we performed a simulated ageing experiment; the bare D1 substrate, a D1 substrate with the Ti10Zr film without binder, and a D1 substrate with the Ti10Zr film with $\mathrm{SiO}_{2}$ binder were irradiated for 14 days in a Suntest chamber with a daylight filter applied. Figure 10 shows that the neat substrate (stable under UVA/B irradiance) and film with $\mathrm{SiO}_{2}$ binder were stable after such prolonged exposure to light. However, pale brown spots appeared on the sample with the photocatalytic layer, lacking the $\mathrm{SiO}_{2}$ binder (Figure 10, middle). A closer look (Figure 10, below) showed crater-like surface structures on the substrate surface, which additionally caused part of the photocatalytic layer to detach at such spots.

Further identification of changes in the samples was conducted by attenuated total reflection (ATR) FTIR spectroscopy (Figure 11). The semi-crystalline polymer which sits on top of the acryl-painted PES fabric shows a complex structure and can present several distinct crystalline phases that are related to different chain conformations; commonly $\alpha-, \beta-$, and $\gamma$-phase (Figure S2). The $\beta$-phase is characterized by a peak at $1273 \mathrm{~cm}^{-1}$ [61], while $\alpha$-phase was detected at 612,967 , and $1383 \mathrm{~cm}^{-1}$. The presence of $\gamma$-phase was also evidenced by the peak at $1240 \mathrm{~cm}^{-1}$, thus confirming the presence of a mixture of $\alpha$-, $\beta-$, and $\gamma$-phase PVDF on the surface of the polymer support, as stated by the producer [62]. 


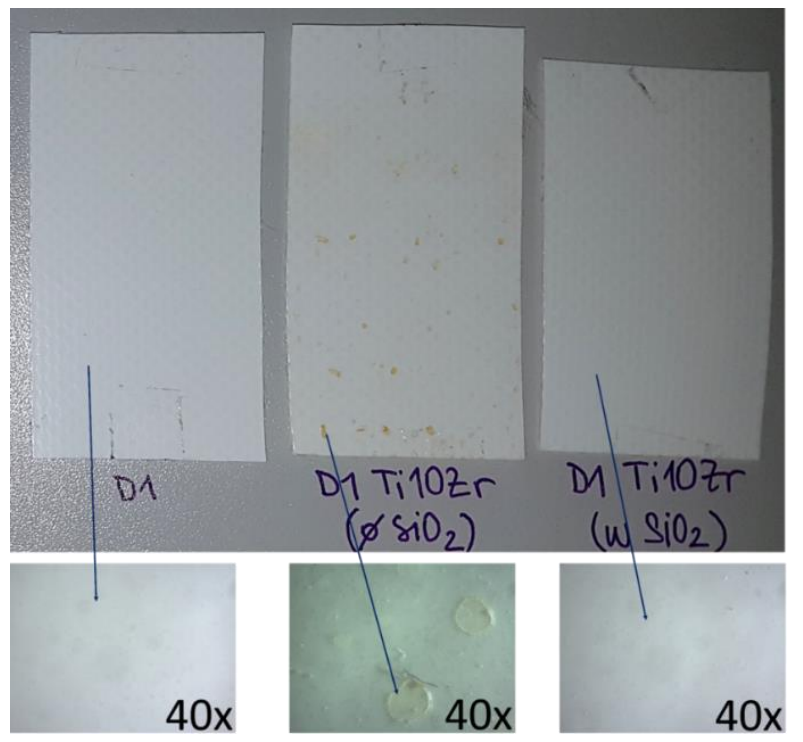

Figure 10. D1 samples exposed to ageing in Suntest chamber with a daylight filter for 14 days. Left: a neat substrate; middle: $\mathrm{Ti} 10 \mathrm{Zr}$ film without $\mathrm{SiO}_{2}$ binder; right: $\mathrm{Ti10Zr}$ with $\mathrm{SiO}_{2}$ and their appearance under higher magnification (below).

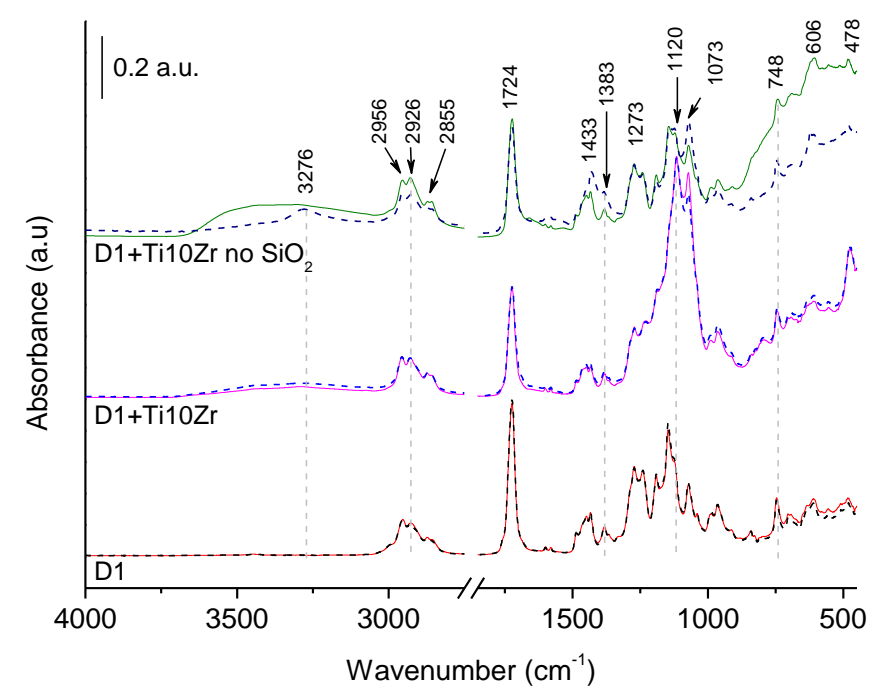

Figure 11. ATR-FTIR spectra of fresh (solid lines) and samples irradiated in Suntest for 14 days (dashed lines).

The $\mathrm{TiO}_{2}$-coated samples show $v(\mathrm{OH})$ at $3600-3200 \mathrm{~cm}^{-1}$, indicating on a more hydroxylated surface, which is in accordance with the CA measurements. It can be observed, however, that the $\mathrm{TiO}_{2}$ films without the presence of $\mathrm{SiO}_{2}\left(\mathrm{Ti} 10 \mathrm{Zr}\right.$ no $\left.\mathrm{SiO}_{2}\right)$ showed even more hydroxylated surface versus $\mathrm{Ti10Zr}$ that contains $\mathrm{SiO}_{2}$ binder. The presence of $\mathrm{SiO}_{2}$ in the film is additionally confirmed by $v(\mathrm{SiO})$ at $1120 \mathrm{~cm}^{-1}$ and $\delta(\mathrm{OSiO})$ at $480 \mathrm{~cm}^{-1}$, while the wide absorption around $700-400 \mathrm{~cm}^{-1}$ is ascribed to $\delta(\mathrm{OTiO})$, due to the presence of $\mathrm{TiO}_{2}$ in the coating layer. Films on other substrates have also been characterised in the same way (Figure S3). They all show the presence of $\delta(\mathrm{OTiO})$ at ca. $550 \mathrm{~cm}^{-1}$ in their structure together with $v(\mathrm{SiO})$ at $1120 \mathrm{~cm}^{-1}$.

Upon simulated ageing, several features in the spectra of $\mathrm{TiO}_{2}$ coated $\mathrm{D} 1$ sample (without $\mathrm{SiO}_{2}$ binder) appeared, i.e., in the sample that exhibited photo-yellowing. In FTIR spectra pointed at the pale brown spot a reduction of absorption bands in the $900-400 \mathrm{~cm}^{-1}$ range-vibrations of $\mathrm{TiO}_{2}$ lattice-is seen; it indicates the $\mathrm{TiO}_{2}$ active layer was masked, probably by organics from the D1 
polymer. Also, the $1073 \mathrm{~cm}^{-1}$ peak increased, which could be ascribed to $v(C F)[63,64]$, suggesting the higher exposure of the $\mathrm{C}-\mathrm{F}$ bonds. The peak at $1383 \mathrm{~cm}^{-1}$ also increased together with $1431 \mathrm{~cm}^{-1}$ band; the latter belongs to $\alpha$-phase of PVDF [61]. Indeed, the $\alpha$-phase shows a more open structure (Figure S2), thus rendering the detection of C-F in a higher number. Second, an increase in the peak at $3266 \mathrm{~cm}^{-1}$ was seen together with a decrease of the $v(\mathrm{OH})$ band. Absorptions at such high frequencies are characteristic for $\mathrm{OH}, \mathrm{FH}$, and $\mathrm{NH}$ stretching vibrations [64]. Nasef et al. [60] claimed that the mechanism upon electron beam irradiation-mediated degradation of PVDF membrane involved the elimination of HF upon crosslinking. This explains the presence of $v(\mathrm{FH})$ in the aged films as HF becomes trapped in-between the PVDF and $\mathrm{TiO}_{2}$ layer. Additionally, Dzinun et al. studied [65] the prolonged UV-stability of $\mathrm{TiO}_{2} / \mathrm{PVDF}$ dual-layer hollow fibre membranes. Similar observations with respect to the ageing of the PVDF were reported and ascribed to a higher number of carbon-carbon double bonds $(-\mathrm{CF}=\mathrm{CH}-)$ formed due to the dehydrofluorination, i.e., the elimination of an $\mathrm{H}-\mathrm{F}$ unit, resulting in the formation of a carbon-carbon double bond. They also reported the appearance of brown colour after prolonged UV-exposure to the consequence of the mentioned phenomenon.

Our data suggest a partially distorted structure of the PVDF polymer and an increase in the $\alpha$-phase fraction; hence, crosslinking probably appeared to some degree, while the brown colour suggests the formation of double bonds in $-(\mathrm{CF}=\mathrm{CH})-$ units. These results corroborate with the WCA measurements, where $\mathrm{D} 1$ coated with $\mathrm{TiO}_{2}$ layer showed increased hydrophobic nature. That layer included a $\mathrm{SiO}_{2}$ binder-this layer (shown in Figure 11), however, also showed a slightly decreased band at $3266 \mathrm{~cm}^{-1}(v(\mathrm{OH})$ band). Hence, the low activity of this substrate can be explained by the decreased concentration of surface -OH species upon irradiation. On the other hand, studies coupling zirconia with titania often suggest on the presence of a heterojunction. The incorporation of $\mathrm{Zr}$ in low quantities commonly gives rise to the creation of defects, which indicates the formation of deep energy states below the conduction band [66]. In this study, however, this is not the case, since the concentration of doping was relatively high $(5,10$, and 20 mol.\%); thus lowering of the band gap was observed due to the increase of the particle sizes. It is thus reasonable to propose a heterojunction formation between $\mathrm{ZrO}_{2}$ and $\mathrm{TiO}_{2}$. Still, this does not lead to increased photocatalytic activity due to unfavorable band edge positions (see Figure S4). Altogether, Zr probably resided on the surface of titania as oxo-clusters, which were not limiting the growth of anatase crystals, partially shaded its surface, and at the same time provided higher abrasive properties.

However, the presence of $\mathrm{SiO}_{2}$ binder inhibited this process, which was proved by the FTIR spectra and photographs (Figure 10) before and after the ageing experiment, and thus it acts beneficially not only at improving the mechanical and optical properties of the films but also extending the stability of the underlying support. Zhou et al. showed [67] the prolonged wettability of $\mathrm{TiO}_{2}$ fluorocarbon composite films when $\mathrm{SiO}_{2}$ was introduced to the system. The improvement was ascribed to the increased surface acidity due to the presence of $\mathrm{Si}-\mathrm{O}-\mathrm{Ti}$ bonds, which causes a more prominent reaction with surface water molecules. The peak at $\sim 950 \mathrm{~cm}^{-1}$, which indicates on this bond was, however, masked in our system by the relatively large absorption of the D1 polymer itself in this region. While this might explain the high activity of the $\mathrm{TiO}_{2}-\mathrm{SiO}_{2}$ system, it does not explain the prolonged UV-resistance. The reasons for such behaviour are under investigation.

\section{Conclusions}

We have demonstrated the applicability of titania-silica-zirconia Ti10Zr sols to the four different polymeric substrates as photocatalytic films for self-cleaning applications. On all of the substrates, we observed self-cleaning property. In general, the transparent PVC and PMMA substrates performed considerably better than acryl coated PES fabrics (D1 and D2) when used as support for low-temperature derived $\mathrm{TiO}_{2}$ films. Film on D1 and D2 substrates were also more hydrophobic i.e., possessed lower concentration of surface-OH species, which is the main reason for lower activity and self-cleaning performance than PVC and PMMA. Fast and visible oriented photocatalytic activity test with Rz ink confirmed the TPA results and water contact angle measurements. 
The role of silica binder in such sols was not only to guarantee excellent mechanical and optical properties, but also to prevent the D1 polymer deterioration, followed by ageing the materials. The D1 substrate, which had a $\mathrm{TiO}_{2}$ layer deposited, was found to be labile to long-term solar-light exposure due to degradation of the PVDF layer on the top of the material. This was prevented with the addition of $\mathrm{SiO}_{2}$ in the photocatalytic layer.

The quantification of the photocatalytic activity by means of contact angle measurements was proven difficult and was much better represented employing a faster method of the oxidation of terephthalic acid deposited on the surface by dip-coating. The presence of zirconia in the photocatalyst layer reduced its photocatalytic activity, but, on the other hand, it significantly increased scratch resistance of the coatings.

The tested substrates are used in a wide area of applications, such as aeroplane windshields, canopies, displays, furniture, rear lights, and windshields in vehicles, greenhouses, sigs, tensile structures, etc. We believe self-cleaning films, as presented here, provide an added value to these materials, making maintenance simpler and saving and improving the lifetime of materials.

Supplementary Materials: The following are available online at http:/ / www.mdpi.com/1996-1944/11/10/1945/s1, Scheme S1: (a) Photoreduction of resazurin to resorufin and further to dihydroresorufin associated with the color changes. Figure S1: Quantified results of the blue color in the RGB color system for the resazurin dye degradation on different substrates: PVC (a), PMMA (b), D1 (c) and D2 (d). Figure S2: Structures of PVDF models, corresponding to two representative crystalline polymorphs ( $\alpha$ - and $\beta$-forms). Figure S3: ATR FTIR spectra of photocatalytic thin films on various substrates; PVC (top left), PMMA (top right), D1 (bottom left) and D2 (bottom right). Figure S4: Schematic representation of the band structures of $\mathrm{TiO}_{2}$ and $\mathrm{ZrO}_{2}$.

Author Contributions: N.V. is the first author as this work is part of her PhD study and she wrote first draft of the manuscript. A.Š. conducted SEM measurements, he provided schemes/graphics for some figures and graphical abstract, he wrote parts of the article and managed preparation of the revised version. D.K. performed BDS measurements and wrote the corresponding part in the article. U.L.Š. supervised research work and writing, finalizing this publication.

Funding: This research was funded by the Slovenian Research Agency through a PhD grant (N. Vodišek), applied research project L2-7630 (Thermo- and photo-active coatings for windows) and research program P1-0134 (Chemistry for sustainable development).

Acknowledgments: Mojca Opresnik from the National Institute of Chemistry is acknowledged for helping with the electron imaging.

Conflicts of Interest: The authors declare no conflicts of interest.

\section{References}

1. Su, B.; Tian, Y.; Jiang, L. Bioinspired Interfaces with Superwettability: From Materials to Chemistry. J. Am. Chem. Soc. 2016, 138, 1727-1748. [CrossRef] [PubMed]

2. Nishimoto, S.; Bhushan, B. Bioinspired self-cleaning surfaces with superhydrophobicity, superoleophobicity and superhydrophilicity. RSC Adv. 2013, 3, 671-690. [CrossRef]

3. Sotelo-Vazquez, C.; Noor, N.; Kafizas, A.; Quesada-Cabrera, R.; Scanlon, D.O.; Taylor, A.; Durrant, J.R.; Parkin, I.P. Multifunctional P-Doped $\mathrm{TiO}_{2}$ Films: A New Approach to Self-Cleaning, Transparent Conducting Oxide Materials. Chem. Mater. 2015, 27, 3234-3242. [CrossRef]

4. De Jesus, M.A.M.L.; da Silva Neto, J.T.; Timò, G.; Paiva, P.R.P.; Dantas, M.S.S.; de Mello Ferreira, A. Superhydrophilic self-cleaning surfaces based on $\mathrm{TiO}_{2}$ and $\mathrm{TiO}_{2} / \mathrm{SiO}_{2}$ composite films for photovoltaic module cover glass. Appl. Adhes. Sci. 2015, 3, 5. [CrossRef]

5. Pfleiderer, S.J.; Lützenkirchen-Hecht, D.; Frahm, R. Crystallization behaviour of $\mathrm{TiO}_{2}-\mathrm{ZrO}_{2}$ composite nanoparticles. J. Sol-Gel Sci. Technol. 2012, 64, 27-35. [CrossRef]

6. Maver, K.; Štangar, U.L.; Černigoj, U.; Gross, S.; Korošec, R.C. Low-temperature synthesis and characterization of $\mathrm{TiO}_{2}$ and $\mathrm{TiO}_{2}-\mathrm{ZrO}_{2}$ photocatalytically active thin films. Photochem. Photobiol. Sci. 2009, 8, 657. [CrossRef] [PubMed]

7. Hirano, M.; Nakahara, C.; Ota, K.; Tanaike, O.; Inagaki, M. Photoactivity and phase stability of $\mathrm{ZrO}_{2}$-doped anatase-type $\mathrm{TiO}_{2}$ directly formed as nanometer-sized particles by hydrolysis under hydrothermal conditions. J. Solid State Chem. 2003, 170, 39-47. [CrossRef] 
8. Vodišek, N.; Ramanujachary, K.; Brezová, V.; Štangar, U.L. Transparent titania-zirconia-silica thin films for self-cleaning and photocatalytic applications. Catal. Today 2017, 287, 142-147. [CrossRef]

9. Štangar, U.L.; Černigoj, U.; Trebše, P.; Maver, K.; Gross, S. Photocatalytic $\mathrm{TiO}_{2}$ coatings: Effect of substrate and template. Monatshefte Fur Chem. 2006, 137, 647-655. [CrossRef]

10. Duc, T.T.; Huong, N.T.M.; Bich, V.T.; Dung, N.D.; Tinh, N.T.; Hoai, T.X. The Effect of $\mathrm{SiO}_{2}$ Addition in Hydrophilic Property of $\mathrm{TiO}_{2}$ Films. In Physics and Engineering of New Materials; Cat, D.T., Pucci, A., Wandelt, K., Eds.; Springer: Berlin/Heidelberg, Germany, 2009; pp. 185-192.

11. Tobaldi, D.M.; Tucci, A.; Škapin, A.S.; Esposito, L. Effects of $\mathrm{SiO}_{2}$ addition on $\mathrm{TiO}_{2}$ crystal structure and photocatalytic activity. J. Eur. Ceram. Soc. 2010, 30, 2481-2490. [CrossRef]

12. Xu, Y.; Zheng, W.; Liu, W. Enhanced photocatalytic activity of supported $\mathrm{TiO}_{2}$ : Dispersing effect of $\mathrm{SiO}_{2}$. J. Photochem. Photobiol. A Chem. 1999, 122, 57-60. [CrossRef]

13. Matsuda, A.; Kotani, Y. Transparent anatase nanocomposite films by the sol-gel process at low temperatures. J. Eur. Ceram. Soc. 2000, 83, 229-231. [CrossRef]

14. Sánchez, B.; Coronado, J.M.; Candal, R.; Portela, R.; Tejedor, I.; Anderson, M.A.; Tompkins, D.; Lee, T. Preparation of $\mathrm{TiO}_{2}$ coatings on PET monoliths for the photocatalytic elimination of trichloroethylene in the gas phase. Appl. Catal. B Environ. 2006, 66, 295-301. [CrossRef]

15. Zhou, L.; Yan, S.; Tian, B.; Zhang, J.; Anpo, M. Preparation of $\mathrm{TiO}_{2}-\mathrm{SiO}_{2}$ film with high photocatalytic activity on PET substrate. Mater. Lett. 2006, 60, 396-399. [CrossRef]

16. Yuranova, T.; Mosteo, R.; Bandara, J.; Laub, D.; Kiwi, J. Self-cleaning cotton textiles surfaces modified by photoactive $\mathrm{SiO}_{2} / \mathrm{TiO}_{2}$ coating. J. Mol. Catal. A Chem. 2006, 244, 160-167. [CrossRef]

17. Veronovski, N.; Rudolf, A.; Smole, M.S.; Kreže, T.; Geršak, J. Self-cleaning and handle properties of $\mathrm{TiO}_{2}$-modified textiles. Fibers Polym. 2009, 10, 551-556. [CrossRef]

18. Montazer, M.; Seifollahzadeh, S. Enhanced self-cleaning, antibacterial and UV protection properties of nano $\mathrm{TiO}_{2}$ treated textile through enzymatic pretreatment. Photochem. Photobiol. 2011, 87, 877-883. [CrossRef] [PubMed]

19. Ortelli, S.; Costa, A.L.; Dondi, $\mathrm{M}$. $\mathrm{TiO}_{2}$ nanosols applied directly on textiles using different purification treatments. Materials 2015, 8, 7988-7996. [CrossRef] [PubMed]

20. Radetić, M. Functionalization of textile materials with $\mathrm{TiO}_{2}$ nanoparticles. J. Photochem. Photobiol. C Photochem. Rev. 2013, 16, 62-76. [CrossRef]

21. Bozzi, A.; Yuranova, T.; Guasaquillo, I.; Laub, D.; Kiwi, J. Self-cleaning of modified cotton textiles by $\mathrm{TiO}_{2}$ at low temperatures under daylight irradiation. J. Photochem. Photobiol. A Chem. 2005, 174, 156-164. [CrossRef]

22. Bozzi, A.; Yuranova, T.; Kiwi, J. Self-cleaning of wool-polyamide and polyester textiles by $\mathrm{TiO}_{2}$-rutile modification under daylight irradiation at ambient temperature. J. Photochem. Photobiol. A Chem. 2005, 172, 27-34. [CrossRef]

23. Meilert, K.T.; Laub, D.; Kiwi, J. Photocatalytic self-cleaning of modified cotton textiles by $\mathrm{TiO}_{2}$ clusters attached by chemical spacers. J. Mol. Catal. A Chem. 2005, 237, 101-108. [CrossRef]

24. Selishchev, D.S.S.; Karaseva, I.P.P.; Uvaev, V.V.V.; Kozlov, D.V.V.; Parmon, V.N.N. Effect of preparation method of functionalized textile materials on their photocatalytic activity and stability under UV irradiation. Chem. Eng. J. 2013, 224, 114-120. [CrossRef]

25. Senić, Ž.; Bauk, S.; Vitorović-Todorović, M.; Pajić, N.; Samolov, A.; Rajić, D. Application of $\mathrm{TiO}_{2}$ nanoparticles for obtaining self-decontaminating smart textiles. Sci. Tech. Rev. 2011, 61, 63-72.

26. Mills, A.; Lee, S.K. A web-based overview of semiconductor photochemistry-based current commercial applications. J. Photochem. Photobiol. A Chem. 2002, 152, 233-247. [CrossRef]

27. Hakki, A.; Yang, L.; Wang, F.; Macphee, D.E. The Effect of Interfacial Chemical Bonding in $\mathrm{TiO}_{2}-\mathrm{SiO}_{2}$ Composites on Their Photocatalytic $\mathrm{NO}_{x}$ Abatement Performance. J. Vis. Exp. 2017. [CrossRef] [PubMed]

28. Ohama, Y.; van Gemert, D. (Eds.) Application of Titanium Dioxide Photocatalysis to Construction Materials; Springer: Dordrecht, The Netherlands, 2011.

29. Žvab, U.; Marušič, M.B.; Štangar, U.L. Microplate-based assays for the evaluation of antibacterial effects of photocatalytic coatings. Appl. Microbiol. Biotechnol. 2012, 96, 1341-1351. [CrossRef] [PubMed]

30. Smitha, V.S.; Manjumol, K.A.; Baiju, K.V.; Ghosh, S.; Perumal, P.; Warrier, K.G.K. Sol-gel route to synthesize titania-silica nano precursors for photoactive particulates and coatings. J. Sol-Gel Sci. Technol. 2010, 54, 203-211. [CrossRef] 


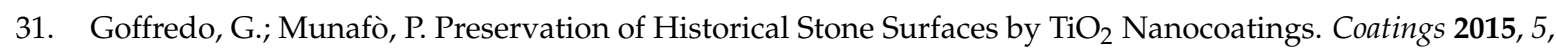
222-231. [CrossRef]

32. Baudys, M.; Krýsa, J.; Zlámal, M.; Mills, A. Weathering tests of photocatalytic facade paints containing ZnO and $\mathrm{TiO}_{2}$. Chem. Eng. J. 2015, 261, 83-87. [CrossRef]

33. Takata, Y.; Hidaka, S.; Cao, J.M.; Nakamura, T.; Yamamoto, H.; Masuda, M.; Ito, T. Effect of surface wettability on boiling and evaporation. Energy 2005, 30, 209-220. [CrossRef]

34. Watanabe, T.; Nakajima, A.; Wang, R.; Minabe, M.; Koizumi, S.; Fujishima, A.; Hashimoto, K. Photocatalytic activity and photoinduced hydrophilicity of titanium dioxide coated glass. Thin Solid Films 1999, 351, 260-263. [CrossRef]

35. Fischer, K.; Gawel, A.; Rosen, D.; Krause, M.; Latif, A.A.; Griebel, J.; Prager, A.; Schulze, A. Low-Temperature Synthesis of Anatase/Rutile/Brookite $\mathrm{TiO}_{2}$ Nanoparticles on a Polymer Membrane for Photocatalysis. Catalysts 2017, 7, 209. [CrossRef]

36. Wei, X.; Yang, Z.; Tay, S.L.; Gao, W. Photocatalytic $\mathrm{TiO}_{2}$ nanoparticles enhanced polymer antimicrobial coating. Appl. Surf. Sci. 2014, 290, 274-279. [CrossRef]

37. Baghriche, O.; Rtimi, S.; Pulgarin, C.; Roussel, C.; Kiwi, J. RF-plasma pretreatment of surfaces leading to $\mathrm{TiO}_{2}$ coatings with improved optical absorption and $\mathrm{OH}$-radical production. Appl. Catal. B Environ. 2013, 131, 65-72. [CrossRef]

38. Latthe, S.; Liu, S.; Terashima, C.; Nakata, K.; Fujishima, A. Transparent, Adherent, and Photocatalytic $\mathrm{SiO}_{2}-\mathrm{TiO}_{2}$ Coatings on Polycarbonate for Self-Cleaning Applications. Coatings 2014, 4, 497-507. [CrossRef]

39. Chemin, J.-B.; Bulou, S.; Baba, K.; Fontaine, C.; Sindzingre, T.; Boscher, N.D.; Choquet, P. Transparent anti-fogging and self-cleaning $\mathrm{TiO}_{2} / \mathrm{SiO}_{2}$ thin films on polymer substrates using atmospheric plasma. Sci. Rep. 2018, 8, 9603. [CrossRef] [PubMed]

40. Rtimi, S.; Pulgarin, C.; Sanjines, R.; Kiwi, J. Innovative semi-transparent nanocomposite films presenting photo-switchable behavior and leading to a reduction of the risk of infection under sunlight. RSC Adv. 2013, 3, 16345-16348. [CrossRef]

41. Manoj, P.K.; Koshy, P.; Vaidyan, V.K. Transparent anatase titania films: A critical study on optical properties. Prog. Nat. Sci. Mater. Int. 2012, 22, 79-85. [CrossRef]

42. Lee, C.S.; Kim, J.; Son, J.Y.; Choi, W.; Kim, H. Photocatalytic functional coatings of $\mathrm{TiO}_{2}$ thin films on polymer substrate by plasma enhanced atomic layer deposition. Appl. Catal. B Environ. 2009, 91, 628-633. [CrossRef]

43. Salmatonidis, A.; Hesselbach, J.; Lilienkamp, G.; Graumann, T.; Daum, W.; Kwade, A.; Garnweitner, G. Chemical Cross-Linking of Anatase Nanoparticle Thin Films for Enhanced Mechanical Properties. Langmuir 2018, 34, 6109-6116. [CrossRef] [PubMed]

44. Xu, F.; Wang, T.; Chen, H.Y.; Bohling, J.; Maurice, A.M.; Wu, L.; Zhou, S. Preparation of photocatalytic $\mathrm{TiO}_{2}$-based self-cleaning coatings for painted surface without interlayer. Prog. Org. Coat. 2017, 113, 15-24. [CrossRef]

45. Veronovski, N.; Sfiligoj-Smole, M. Functionalization of lyocell fibers with $\mathrm{TiO}_{2}, \mathrm{SiO}_{2}$, and GLYMO. Fibers Polym. 2010, 11, 545-550. [CrossRef]

46. Li, W.-D.; Gao, J.; Wang, L. Enhancement of durable photocatalytic properties of cotton/polyester fabrics using $\mathrm{TiO}_{2} / \mathrm{SiO}_{2}$ via one step sonosynthesis. J. Ind. Text. 2017, 46, 1633-1655. [CrossRef]

47. Korte, D.; Franko, M. Application of complex geometrical optics to determination of thermal, transport, and optical parameters of thin films by the photothermal beam deflection technique. J. Opt. Soc. Am. A 2015, 32, 61-74. [CrossRef] [PubMed]

48. Černigoj, U.; Kete, M.; Štangar, U.L. Development of a fluorescence-based method for evaluation of self-cleaning properties of photocatalytic layers. Catal. Today 2010, 151, 46-52. [CrossRef]

49. Thamaphat, K.; Limsuwan, P.; Ngotawornchai, B. Phase Characterization of $\mathrm{TiO}_{2}$ Powder by XRD and TEM. Nat. Sci. 2008, 42, 357-361.

50. Kwon, C.H.; Shin, H.; Kim, J.H.; Choi, W.S.; Yoon, K.H. Degradation of methylene blue via photocatalysis of titanium dioxide. Mater. Chem. Phys. 2004, 86, 78-82. [CrossRef]

51. Di Paola, A.; Bellardita, M.; Palmisano, L. Brookite the Least Known $\mathrm{TiO}_{2}$ Photocatalyst. Catalysts 2013. [CrossRef]

52. Carnegie, M.R.; Sherine, A.; Sivagami, D.; Sakthivel, S. Anti-reflection coatings with enhanced abrasion and scratch resistance properties. J. Sol-Gel Sci. Technol. 2016, 78, 176-186. [CrossRef] 
53. Prado, R.; Beobide, G.; Marcaide, A.; Goikoetxea, J.; Aranzabe, A. Development of multifunctional sol-gel coatings: Anti-reflection coatings with enhanced self-cleaning capacity. Sol. Energy Mater. Sol. Cells 2010, 94, 1081-1088. [CrossRef]

54. Helsch, G.; Deubener, J. Compatibility of antireflective coatings on glass for solar applications with photocatalytic properties. Sol. Energy 2012, 86, 831-836. [CrossRef]

55. Li, R.; Boudot, M.; Boissière, C.; Grosso, D.; Faustini, M. Suppressing Structural Colors of Photocatalytic Optical Coatings on Glass: The Critical Role of $\mathrm{SiO}_{2}$. ACS Appl. Mater. Interfaces 2017, 9, 14093-14102. [CrossRef] [PubMed]

56. Murphy, A.B. Band-gap determination from diffuse reflectance measurements of semiconductor films, and application to photoelectrochemical water-splitting. Sol. Energy Mater. Sol. Cells 2007, 91, 1326-1337. [CrossRef]

57. Lin, H.; Huang, C.; Li, W.; Ni, C.; Shah, S.; Tseng, Y. Size dependency of nanocrystalline $\mathrm{TiO}_{2}$ on its optical property and photocatalytic reactivity exemplified by 2-chlorophenol. Appl. Catal. B Environ. 2006, 68, 1-11. [CrossRef]

58. Cao, X.; Ma, J.; Shi, X.; Ren, Z. Effect of $\mathrm{TiO}_{2}$ nanoparticle size on the performance of PVDF membrane. Appl. Surf. Sci. 2006, 253, 2003-2010. [CrossRef]

59. Mirabedini, A.; Mirabedini, S.M.; Babalou, A.A.; Pazokifard, S. Synthesis, characterization and enhanced photocatalytic activity of $\mathrm{TiO}_{2} / \mathrm{SiO}_{2}$ nanocomposite in an aqueous solution and acrylic-based coatings. Prog. Org. Coat. 2011, 72, 453-460. [CrossRef]

60. Nasef, M.M.; Saidi, H.; Dahlan, K.Z.M. Investigation of electron irradiation induced-changes in poly(vinylidene fluoride) films. Polym. Degrad. Stab. 2002, 75, 85-92. [CrossRef]

61. Cai, X.; Lei, T.; Sun, D.; Lin, L. A critical analysis of the $\alpha, \beta$ and $\gamma$ phases in poly(vinylidene fluoride) using FTIR. RSC Adv. 2017, 7, 15382-15389. [CrossRef]

62. Zrim, G.; Mihelčič, M.; Perše, L.S.; Orel, B.; Simončič, B.; Kunič, R. Light distribution in air-supported pneumatic structures: Comparison of experimental and computer calculated daylight factors. Build. Environ. 2017, 119, 110-127. [CrossRef]

63. Coates, J. Interpretation of Infrared Spectra, A Practical Approach. Encycl. Anal. Chem. 2006, 1-23. [CrossRef]

64. Nakamoto, K. Infrared and Raman Spectra of Inorganic and Coordination Compounds; Wiley: Chichester, UK, 2009.

65. Dzinun, H.; Othman, M.H.D.; Ismail, A.F.; Puteh, M.H.; Rahman, M.A.; Jaafar, J. Stability study of $\mathrm{PVDF} / \mathrm{TiO}_{2}$ dual layer hollow fibre membranes under long-term UV irradiation exposure. J. Water Process Eng. 2017, 15, 78-82. [CrossRef]

66. Guerrero-Araque, D.; Ramírez-Ortega, D.; Acevedo-Peña, P.; Tzompantzi, F.; Calderón, H.A.; Gómez, R. Interfacial charge-transfer process across $\mathrm{ZrO}_{2}-\mathrm{TiO}_{2}$ heterojunction and its impact on photocatalytic activity. J. Photochem. Photobiol. A Chem. 2017, 335, 276-286. [CrossRef]

67. Zhou, J.; Tan, Z.; Liu, Z.; Jing, M.; Liu, W.; Fu, W. Preparation of transparent fluorocarbon $/ \mathrm{TiO}_{2}-\mathrm{SiO}_{2}$ composite coating with improved self-cleaning performance and anti-aging property. Appl. Surf. Sci. 2017, 396, 161-168. [CrossRef]

(C) 2018 by the authors. Licensee MDPI, Basel, Switzerland. This article is an open access article distributed under the terms and conditions of the Creative Commons Attribution (CC BY) license (http://creativecommons.org/licenses/by/4.0/). 